Occupational therapists working in community mental health teams (CMHTs) are often challenged to justify their unique approach to health through occupation, within an environment that tends to press for generic working. Such a challenge requires practitioners to identify and communicate evidence that supports their unique occupational contribution. In the absence of extensive robust and relevant research evidence, it is suggested that the contribution of theoretical evidence be considered.

This paper, therefore, explores the potential of occupational justice and its related concepts to provide the profession with a theoretical justification for occupational therapists adopting an occupation-focused role in CMHTs. It begins with an overview of how CMHTs, generic working and occupational science have evolved. The concept of occupational justice and its related occupational risk factors are then analysed in relation to practice. The potential conflict between the professional commitment to client-centred practice and the generic worker model is also discussed. The paper concludes with recommendations for further exploration and consideration.

\title{
Sustaining a Focus on Occupation in Community Mental Health Practice
}

\author{
Anna Pettican and Wendy Bryant
}

\section{Introduction}

The trend for occupational therapists to perform a predominantly generic role when working as part of a community mental health team (CMHT) has been an area of discussion over recent years, with concerns focusing primarily on the potential loss of core skills and, ultimately, of professional identity (Craik et al 1998a, Taylor and Rubin 1999, Hughes 2001, Parker 2001, Hayden 2004, Reeves and Summerfield Mann 2004). Occupational therapy has a unique focus on occupation, with a fundamental belief that occupation is central to maintaining and promoting people's health and wellbeing (Creek 2003, World Federation of Occupational Therapists 2004). The lack of research evidence supporting occupational therapy practice in the community mental health setting has undoubtedly contributed to the profession's difficulties in justifying an occupation-focused, rather than a generic, role and is a problem that has been acknowledged by the College of Occupational Therapists (COT) (Craik 1998).

The College of Occupational Therapists' subsequent position paper on the way ahead for research, education and practice in mental health aimed to rectify this by identifying areas for future research (Craik et al 1998b). However, when searching for evidence to underpin their role and practice, occupational therapists in the field of mental health have encountered difficulties.
It is therefore suggested that the potential of theory to provide guidance and justification for clinical practice should be considered (McColl 2003). The contribution of occupational science to occupational therapy practice is timely (Wilcock 2001) and there is further scope for exploration in relation to occupational therapy in community mental health. Following an analysis of the drivers for current practice, this paper focuses on occupational justice. The concept is explained and examined for its relevance to contemporary mental health practice.

\section{Background}

\section{Community care}

There has been a dramatic change in the way that mental health services have been delivered over the last three decades, with a definitive shift from custodial and institutionalised environments to community-based services in response to the National Health Service and Community Care Act (Department of Health [DH] 1990a, Bell and Lindley 2005). This change in service delivery has resulted in CMHTs being established in order to support those people with mental health problems who do not require long-term hospital care. The National Health Service and Community Care Act (DH 1990a) and the Care Programme Approach (DH 1990b) both attempted to implement a more coordinated and consistent approach to 
community care by providing each service user with a single designated person, currently known as a 'care coordinator'.

The reasoning behind this decision was that it would allow the service user to develop a consistent and effective relationship with his or her designated care coordinator who, regardless of professional discipline, would be ultimately responsible for considering all aspects of the service user's needs (Onyett 2005). The intention was that the care coordinator would seek support from an appropriate professional if the service user's needs fell outside the care coordinator's professional skill base. However, in reality, heavy workloads have meant that this has not always been possible, resulting in service users having access only to the services that their designated care coordinator is skilled in providing (Patmore and Weaver 1992, Harries 1998).

Experience of working in a CMHT has also suggested that the ongoing difficulties with staff recruitment and retention in the National Health Service have often presented problems with continuity when only one professional has been involved in a service user's care. This situation has resulted in limitations to the formation of an effective relationship between the care coordinator and the service user.

\section{Shared capabilities}

The National Service Framework for Mental Health (DH 1999) clarified the role of CMHTs as working with people with severe and enduring mental health problems, while those with more common mental health problems would be provided for in primary care. The Sainsbury Centre for Mental Health's (2001) Capable Practitioner Report then set out the capabilities that every mental health worker should possess. Although this report contained several capabilities relating closely to occupational therapy philosophy and approaches, it did not provide specific guidance as to the profession to which any of the capabilities related. This report has now been updated by The Ten Essential Shared Capabilities (DH 2004) and, although this publication aimed to address the limitations of the Capable Practitioner Report (Sainsbury Centre for Mental Health 2001), it is disappointing that it is focused on 10 'shared' generic capabilities rather than profession-specific ones. The tendency for policy documents relating to community mental health care to refer to all 'mental health professionals' together (except for those relating to public safety) is frustrating. It remains to be seen whether or not the occupational therapy profession will seize this as an opportunity to communicate and demonstrate its unique contribution to contemporary community mental health practice.

\section{Three methods of working}

Recent literature has reported that for occupational therapists in CMHTs three methods of working have emerged: working specifically as an occupational therapist; working solely as a generic care coordinator; and working in a way that combines both of these roles to varying degrees (Harries and Gilhooly 2003).
Several studies have reported on the tendency for occupational therapists to perform generic duties (Craik et al 1998a, Meeson 1998a, 1998b). In 1998, the College of Occupational Therapists published the following guidance, 'Occupational therapists should spend the majority of their clinical time working as occupational therapists and not as generalist mental health workers' (Craik et al 1998b, p391), and also stated the eventual aim of providing '... precise guidelines about the percentage of clinical time occupational therapists should spend working as occupational therapists rather than as generalist mental health workers' (Craik et al 1998b, p392). However, this statement has since been retracted: '... the College has not issued, and probably would not issue, guidance about what constitutes "the majority of clinical time"' (Fowler Davis and Ilott 2002).

Reassuringly, the recently published 10-year strategy for occupational therapy in mental health services (COT 2006) included a consideration of the difficulties that occupational therapists can encounter when working within multidisciplinary teams. It contained a number of key messages for occupational therapists, including the routine use of occupational terminology to communicate the relationship between health and occupation to service users, carers, colleagues and service commissioners.

There is an obvious tension between the Government's drive towards generic working and the College of Occupational Therapists' guidance. However, also in support of occupational therapists having a defined role in CMHTs is the empirical evidence regarding effective teamwork. This rejects generic working in favour of individuals having clearly defined roles and responsibilities (Øvretveit 1993, West and Slater 1994, Molyneux 2001). Onyett (2005) has also highlighted the importance of respecting personal and professional values in enabling CMHT members to find and sustain meaning in their daily work.

In the light of the above guidance and literature, it appears that attention must be turned towards how an occupation-focused approach can be sustained by occupational therapists while fulfilling their role as a fully integrated member of the team. This paper now explores theories that could underpin and justify occupation-focused practice in CMHTs.

\section{Occupational science}

Occupational science and occupational therapy are similar in that they both focus on occupation. They differ in that occupational science is an academic discipline and occupational therapy is a profession (Larson et al 2003). Put simply, occupational science can be defined as 'the study of the human as an occupational-being' (Yerxa et al 1989, p6). It is important to emphasise that occupational science is not a new idea and that its foundation knowledge has been drawn primarily from occupational therapy's original philosophies and beliefs (Yerxa et al 1989). In the past, the profession is believed to have lost sight of the value of occupation in relation to health and wellbeing due to its alignment with the medical model. This resulted 
in both clinical practice and the profession's development being restricted, since the profession had lost contact with its original philosophies and beliefs (Wilcock 2001).

One of the founding aims of occupational science was to refocus the occupational therapy profession on occupation (Yerxa et al 1989). This was representative of a wider paradigm shift within health care: from a reductionist medical approach to a more holistic one that acknowledged a person's wider psychosocial needs (Wilcock 2001).

Yerxa et al (1989) introduced occupational science as '.. an emerging basic science which supports the practice of occupational therapy' (p1) and also suggested that '... occupational science could provide practitioners with support for what they do, justify the significance of occupational therapy to health, and differentiate occupational therapy from other professions' (p3). These statements would appear to underpin an occupation-focused role for occupational therapists working in CMHTs.

Mounter and Ilott (1997) have reported that occupational science has had an impact on the profession's thinking, education and research in the United Kingdom, but it is worth considering if there is yet much evidence of it having permeated and informed occupational therapy practice. Certainly, Kielhofner (1997) has encouraged consideration of how the knowledge and theories that are emerging from occupational science can be usefully applied to everyday clinical practice.

\section{Occupational justice: doing things fairly}

An occupational science concept that appears to be particularly relevant to mental health practice is that of occupational justice. Occupational justice can be defined as:

recognising and providing for the occupational needs of individuals and communities as part of a fair and empowering society (Wilcock and Townsend 2000, p84).

The concept of occupational justice is strongly aligned with social justice but:

whilst social justice addresses the social relations and social conditions of life, occupational justice addresses what people do in their relationships and conditions of living (Wilcock and Townsend 2000, p84).

Occupational justice arose out of a belief that social justice lacked a consideration of society's occupational injustices; in other words, the imbalance of some individuals having multiple occupational choices and opportunities, whilst others led empty, meaningless lives with severely restricted, or even in some cases no, choice in the occupations in which they engaged (Townsend and Wilcock 2004). It is important to emphasise the close relationship between occupation and justice. Everyday life is typified by engagement in various occupations: limitations in engaging in such occupations or opportunities to do so are what ultimately determine the future restriction or development of individuals, communities and nations. Occupational justice calls for a respect for difference, that people should be enabled to do things that are not only meaningful and valuable but also relate to their particular skills and potential (Wilcock and Townsend 2000).

Occupational justice is a concept that is considered particularly relevant to community mental health practice because it encapsulates many of the issues that people with mental health problems experience. Just like anyone else, people with mental health problems strive to experience feelings of purposefulness, acceptance and belonging (Grady 1995, Laliberte-Rudman et al 2000, Rebeiro et al 2000).

However, to a large extent society does not respect individual difference in occupational terms and, as a consequence, those people experiencing mental health problems are very often marginalised (Grady 1995). Although the social justice movement has successfully advocated for the inclusion of marginalised groups, acknowledging the importance of social life and acceptance for survival, a recognition of the occupational perspective in the achievement of a just society is less well established (Wilcock 2006).

Recent initiatives to secure social inclusion have recognised this perspective, suggesting ways of addressing occupational injustices that have created barriers for people with mental health problems in accessing work, education and community life (DH 1999, Office of the Deputy Prime Minister 2004). Occupational therapists working in CMHTs are frequently involved in assisting people to overcome such injustices and, therefore, further exploration of occupational justice and its related concepts appears to be pertinent. The potential outcomes of occupational injustices are occupational deprivation, occupational imbalance, occupational alienation, and disease at individual and society level. The first three outcomes have been termed 'occupational risk factors' (Townsend and Wilcock 2004) and will now be analysed further.

\section{Occupational deprivation: being prevented from participating in occupations}

Occupational deprivation has been defined as:

a state in which a person or group of people are unable to do what is necessary and meaningful in their lives due to external restrictions (Whiteford 2000, p200).

It is important to clarify the 'external restrictions' aspect of occupational deprivation: it is a state that arises due to external factors rather than any internal limitations of the individual. In other words, it is something or someone external to the individual that is doing the depriving. Occupational deprivation can arise due to a number of external restrictions; for example, unemployment, poverty, unsuitable housing or discrimination (Whiteford 2004). When considering anecdotal evidence from practice, such as the continuing difficulties that people with mental health problems encounter in trying to obtain employment due to discrimination and stigma, it is undeniable that 
people with mental health problems frequently experience occupational deprivation.

Occupational therapists working in CMHTs are often involved in providing interventions that tackle occupational deprivation, although they may not have previously conceptualised them as such; for example, assisting someone in completing a college course application or providing a supportive community-based group that facilitates members engaging in mainstream leisure occupations and contexts. Hayden (2004) has provided a comprehensive description of such a group, a community-based 'community resources' group. Although she does not refer to occupational deprivation specifically, occupational science and occupational therapy theory are given as rationales for the group. Group members were service users from a CMHT and the group seemed ideally designed to overcome some of the effects of occupational deprivation. It provided group members with the opportunity to engage in mainstream leisure occupations, exercise choice, establish new friendships and experience a sense of belonging within their own community. Over the weeks that the group was running, the members were provided with the opportunity to engage in a variety of occupations (for example, tenpin bowling, go-karting, and visiting art galleries and the cinema). Facilitating staff gradually dropped out of the group as the group members became more confident and less reliant on their support and presence to access such resources (Hayden 2004).

The concept of occupational deprivation also complements the current Government drive towards social inclusion (Office of the Deputy Prime Minister 2004). This drive aims to overcome the discrimination and stigma that people with mental health problems experience, in order to facilitate their having equal access to mainstream employment, education and leisure opportunities. Given that this Government policy is in place, and that occupational therapists in CMHTs already seem to be providing interventions that overcome the effects of occupational deprivation, it appears to be worth considering whether or not this concept, although seemingly relevant, is necessary for clinical practice. When addressing this point, it is important to reflect on the profession's continuing difficulty in gaining recognition for its occupational focus, not only at a service level but also in national publications such as the report of the Sainsbury Centre for Mental Health (2001). It is therefore suggested that such recognition and ownership is dependent on using this terminology in all aspects of daily practice.

\section{Occupational imbalance: compromising health}

Occupational imbalance is another occupational risk factor that can occur due to occupational injustice. Occupational imbalance has been defined as:

an individual or group experience in which health and quality of life are compromised because of being over-occupied or under-occupied (Christiansen and Townsend 2004, p278).

The concept of occupational imbalance is based on the belief that having a balance in terms of the types of occupation that we engage in (for example, self-care, productivity and leisure) is necessary for achieving health and wellbeing (Gramm 1987). Associated with occupational deprivation, and also the experience of mental illness itself, it concerns the difficulties that people with mental health problems encounter when trying to achieve a balance in terms of how they spend their time.

Stewart and Wheeler (2005) have created the 'Bolsover recovery model' as a method of service delivery that will potentially enable people with mental health problems to achieve a more balanced lifestyle. This model is underpinned by the Model of Occupational Performance (Reed 1984) and conceptualises people as engaging in occupations described in the three key performance areas of self-care, productivity and leisure. There are suggestions of various services relating to the three performance areas (for example, self-care, cooking skills sessions; productivity, supported work placements; and leisure, an outdoor pursuits group). However, these three performance areas or categories of occupations have been questioned by Primeau (1996), from a feminist perspective, in relation to household work, which could be categorised as self-care, productivity or leisure, depending on the particular occupation and its meaning to the individual.

Wilcock (2006) analysed the difficulties associated with categorising occupations according to externally and socially perceived functions. In her view, health through occupational balance requires the use and development of individual capabilities, rather than just focusing on time use. This is intrinsically related to a person's physical, mental, social, emotional and spiritual life, with occupational imbalance being a consequence of dysfunction or lack of opportunity in any of these areas. This may be a collective experience, such as the prolonged periods of inactivity commonly associated with depression, but it will be individually expressed (Wilcock 2006). A more flexible view, such as this one, is perhaps more relevant to people with mental health problems, who at times may not be capable of performing occupations that are related to all three of the performance areas or find them meaningful.

Interestingly, although the National Health Service appears to have acknowledged the importance of enabling its employees to achieve a healthy occupational balance through the publication of an Improving Working Lives policy (DH 2000), it has not yet advocated it formally for its service users. Westhorp (2003) described occupational imbalance as an area that still requires development and research. As such, it may well be an area of opportunity, where occupational therapists working in CMHTs can clinically demonstrate, research and communicate their unique occupation-focused approach to others, at both a service and a public health level.

\section{Occupational alienation: performing occupations that lack meaning and purpose}

Linking closely with the theory of occupational imbalance is the third occupational risk factor of occupational alienation. Occupational alienation has been described as people 
experiencing everyday life to be meaningless and purposeless (Townsend and Wilcock 2004). A meaningful occupation is determined as such by the individual and influenced by external factors such as culture. Occupational alienation is believed to arise out of the subjective experiences of:

isolation, powerlessness, frustration, loss of control, and estrangement from society or self as a result of engagement in occupation that does not satisfy inner needs (Wilcock 2006, p343).

As outlined above, people with mental health problems are at risk of occupational deprivation and occupational imbalance. Both of these concepts are associated with the experience of occupational alienation. For example, service users from CMHTs may well struggle to experience a sense of control over their lives owing to their symptoms and also stigma and discrimination, which prevent them from being able to engage in any purposeful employment. Furthermore, this may then lead to poverty, isolation and a negative sense of identity, having a further impact on their ability to engage in occupations that they find meaningful and purposeful.

Engaging people in meaningful and purposeful occupations in order to promote health and wellbeing is a basic tenet of the occupational therapy profession (World Federation of Occupational Therapists 2004) and, as such, occupational therapists are ideally placed to provide interventions and services in this area. A study by the second author (Bryant et al 2004) described the potential for mental health day services to both foster and overcome service users' experiences of occupational alienation, based on service users' perspectives. Day services can come with the cost of dependency, especially if institutional or organisational agendas predominate. There is a need to provide services that are flexible and supportive, and promote a sense of belonging without fostering occupational alienation. Occupational therapists in CMHTs are well placed to offer such services by providing support and interventions within the service user's own context, of both his or her home and the wider community. Interventions can also be graded to promote eventual independence, such as in Hayden's (2004) group example provided above, where staff withdrew from the group as members became less reliant on their support. Such strategies enable service users to achieve health and wellbeing through occupation, whilst also promoting a sense of belonging to both the group and their wider community.

Occupational deprivation, occupational imbalance and occupational alienation, along with the umbrella concept of occupational injustice, thus offer a means of understanding people's experiences in mental health services. Being occupation-focused concepts, these factors could suggest how to frame interventions, by engaging in a process of enabling opportunity, balancing occupations and belonging. This process requires further consideration of client-centred practice, which is a central commitment of the occupational therapy profession
(Canadian Association of Occupational Therapists 1991, COT 2005). It is therefore felt to be important that an exploration of it in relation to the generic mental health worker model (DH 1995) is undertaken.

\section{Client-centred practice versus the generic worker model}

The generic mental health worker model (DH 1995) appears to be at odds with the concept of client-centred practice, apparently promoting a jack of all trades and master of none' method of service delivery. As discussed above, heavy workloads in CMHTs often mean that referral for profession-specific work is not possible (for example, a nurse care coordinator referring service users to an occupational therapist specifically for support with developing independent living skills) (Patmore and Weaver 1992, Harries 1998). In a climate where the Government is now aiming to listen to the voices and needs of service users (DH 1990, 1999), it therefore seems contradictory that, ultimately, the service being provided is driven by the professional capacity of individual mental health workers rather than by identified service user need. The often transitory nature of staff in the National Health Service also fails to support the idea of service users having one designated worker, with whom they can build a relationship and work alongside over a long period.

Occupational justice is based on the belief that humans are autonomous occupational beings and its principles of diversity, inclusion and shared advantage in occupational participation (Townsend and Wilcock 2004) appear to fit well with occupational therapy's commitment to client-centred practice. However, there is an obvious tension between using occupational theory to define professional boundaries and maintaining client-centred practice. Indeed, it could be said that by adopting an 'occupational focus', occupational therapists are, by definition, setting the therapeutic agenda and abandoning their commitment to client-centred practice. Nevertheless, it could equally be argued that acknowledging professional capacity, limitations and specialisms is necessary at both an individual and a profession level, in order to achieve efficient practice and service delivery. It is always going to be unrealistic that any single professional can meet all the needs of every service user on his or her caseload. In the current environment of the National Health Service, where resource constraints mean that referral for profession-specific work is not always going to be possible, it is suggested that, in the case of generic working, occupational therapists should create strategies to allow for an occupational focus or abandon it altogether.

It is inevitable and necessary, in terms of effective teamwork, that occupational therapists working in CMHTs will complete some generic duties. However, the above theoretical analysis has demonstrated that 
working entirely generically will not best serve service users or the future development of the occupational therapy profession. People with mental health problems can experience a range of occupational needs and it is essential that skilled professionals be provided to address them.

\section{Conclusion}

This paper has presented the concept of occupational justice and the contributing risk factors of occupational deprivation, occupational imbalance and occupational alienation. Analysis of these concepts, illustrated by examples of everyday working situations, has demonstrated potential to underpin and justify occupation-focused practice in the contemporary community mental health setting. Potential conflicts between professional philosophies and generic working have also been identified. It is suggested that the occupational therapy profession reconsiders occupational justice, because this is an area that has been identified as requiring further development and research (Wilcock 2006).

The future of the occupational therapy profession in CMHTs is dependent on occupational therapists understanding and using occupational theories to underpin their everyday practice. Such theories foster a unique, occupation-focused contribution and can be easily explained to colleagues, managers, commissioners and service users. The College of Occupational Therapists has asserted that the majority of occupational therapists' clinical time should be spent working as occupational therapists (Craik et al 1998b) and, with the recent support of the strategy for occupational therapy in mental health services (COT 2006), occupational therapists in CMHTs must seek ways of achieving and sustaining this.

It remains to be seen whether or not occupational therapists will embrace occupational science as a theoretical means of underpinning and justifying their everyday practice. The issues explored above have been occurring in our society for many years, but what is new is the opportunity to frame such concepts in occupational terms. Such an opportunity can potentially provide the profession with a universal language and also provide a basis for education, research, practice and development. Perhaps most importantly, it would provide a way of communicating and justifying occupational therapy's unique approach to others. It is an opportunity and it is ours for the taking.

\section{Acknowledgements}

The first author would like to thank all those who have supported and encouraged her in her learning. She also wishes to thank the HSA Charitable Trust Short Course Grant fund, which provided financial assistance towards the occupational science module fees. This paper is based on work submitted in part fulfilment for the MScOT at Brunel University. Thanks also to the two anonymous BJOT article reviewers for their helpful and constructive comments.

\section{References}

Bell A, Lindley P, eds (2005) Beyond the water towers. London: Sainsbury Centre for Mental Health.

Bryant W, Craik C, McKay E (2004) Living in a glasshouse: exploring occupational alienation. Canadian Journal of Occupational Therapy, 71(5), 282-89.

Canadian Association of Occupational Therapists (1991) Occupational therapy guidelines for client-centred practice. Toronto: Canadian Association of Occupational Therapists.

Christiansen CH, Townsend EA (2004) Introduction to occupation, the art and science of living. Upper Saddle River, NJ: Prentice Hall.

College of Occupational Therapists (2005) College of Occupational Therapists: Code of ethics and professional conduct. London: COT.

College of Occupational Therapists (2006) Recovering ordinary lives: the strategy for occupational therapy in mental health services 2007-2017, a vision for the next 10 years (Core). London: COT.

Craik C (1998) Occupational therapy in mental health: a review of the literature. British Journal of Occupational Therapy, 61(5), 186-92.

Craik C, Chacksfield J, Richards G (1998a) A survey of occupational therapy practitioners in mental health. British Journal of Occupational Therapy, 61(5), 227-33.

Craik C, Austin C, Chacksfield J, Richards G, Schell D (1998b) College of Occupational Therapists: Position paper on the way ahead for research, education and practice in mental health. British Journal of Occupational Therapy, 61(9), 390-92.

Creek J (2003) Occupational therapy defined as a complex intervention. London: COT.

Department of Health (1990a) National Health Service and Community Care Act. London: HMSO.

Department of Health (1990b) Caring for people. The CPA for people with a mental illness referred to specialist mental health services. Joint Health/ Social Services Circular. C(90)23/LASSL(90)11. London: DH.

Department of Health (1995) Building bridges. London: HMSO.

Department of Health (1999) National Service Framework for Mental Health. London: HMSO.

Department of Health (2000) Improving working lives standard. London: HMSO.

Department of Health (2004) The ten essential shared capabilities. London: HMSO.

Fowler Davis S, llott I (2002) Mental health update. (Letter.) British Journal of Occupational Therapy, 65(5), 252.

Grady A (1995) Building inclusive community: a challenge for occupational therapy. American Journal of Occupational Therapy, 49(4), 300-10.

Gramm WS (1987) Labor, work and leisure: human well-being and the optimal allocation of time. Journal of Economic Issues, 21, 167-88.

Harries P (1998) Community mental health teams: occupational therapists' changing role. British Journal of Occupational Therapy, 61(5), 219-20.

Harries PA, Gilhooly K (2003) Generic and specialist occupational therapy casework in community mental health teams. British Journal of Occupational Therapy, 66(3), 101-109.

Hayden R (2004) Social inclusion through occupation in community mental health. In: M Molineux, ed. Occupation for occupational therapists. Oxford: Blackwell, 122-36.

Hughes J (2001) Occupational therapy in community mental health teams: a continuing dilemma? Role theory offers an explanation. British Journal of Occupational Therapy, 64(1), 34-35. 
Kielhofner G (1997) The future of occupational therapy's conceptual foundations. In: G Kielhofner, ed. Conceptual foundations of occupational therapy. 2nd ed. Philadelphia: FA Davis, 321-41.

Laliberte-Rudman D, Yu B, Scott E, Pajouhandeh P (2000) Exploration of the perspectives of persons with schizophrenia regarding quality of life. American Journal of Occupational Therapy, 54(2), 137-47.

Larson E, Wood W, Clark F (2003) Occupational science: building the science and practice of occupation through an academic discipline. In: EB Crepeau, ES Cohn, BA Boyt Schell, eds. Willard and Spackman's occupational therapy. 10th ed. London: Lippincott Williams and Wilkins, 15-26.

McColl MA (2003) The occupational therapy toolbox: uses of theory in occupational therapy. In: MA McColl, MC Law, L Doubt, N Pollock, D Steward, eds. Theoretical basis of occupational therapy. 2nd ed. Thorofare, NJ: Slack, 7-10.

Meeson B (1998a) Occupational therapy in community mental health, part 1 : intervention choice. British Journal of Occupational Therapy, 61(1), 7-12.

Meeson B (1998b) Occupational therapy in community mental health, part 2: factors influencing intervention choice. British Journal of Occupational Therapy, 61(2), 57-62.

Molyneux J (2001) Interprofessional team working: what makes teams work well? Journal of Interprofessional Care, 15(1), 28-35.

Mounter C, llott I (1997) Occupational science: a journey of discovery in the United Kingdom. Journal of Occupational Science: Australia, 4(2), 50-55.

Office of the Deputy Prime Minister (2004) Mental health and social exclusion. Available at: $h$ ttp://www.socialexclusion.gov.uk/downloaddoc.asp?id=134 Accessed on 07.05.06.

Onyett S (2005) Mental health teams - hitting the targets, missing the point? In: A Bell, P Lindley, eds. Beyond the water towers. The unfinished revolution in mental health services 1985-2005. London: Sainsbury Centre for Mental Health, 91-101.

Øvretveit J (1993) Coordinating community care: multidisciplinary teams and care management. Milton Keynes: Open University Press.

Parker H (2001) The role of occupational therapists in community mental health teams: generic or specialist? British Journal of Occupational Therapy, 64(12), 609-11.

Patmore C, Weaver T (1992) Improving community services for serious mental disorders. Journal of Mental Health, 1, 107-15.

Primeau $L$ (1996) Work versus nonwork. The case of household work. In: R Zemke, F Clark, eds. Occupational science: the evolving discipline. Philadelphia: FA Davis, 57-69.

Reed K (1984) Models of practice in occupational therapy. Baltimore: Williams and Wilkins.

Reeves S, Summerfield Mann L (2004) Overcoming problems with generic working for occupational therapists based in community mental health settings. British Journal of Occupational Therapy, 67(6), 265-68.
Rebeiro K, Day D, Semeniuk B, O'Brien M, Wilson B (2000) Northern initiative for social action: an occupation-based mental health programme. American Journal of Occupational Therapy, 55(5), 493-500.

Sainsbury Centre for Mental Health (2001) The capable practitioner report. London: Sainsbury Centre for Mental Health.

Stewart L, Wheeler K (2005) Occupation for recovery. Occupational Therapy News, 13(11), 24-25.

Taylor A, Rubin R (1999) How do occupational therapists define their role in a community mental health setting? British Journal of Occupational Therapy, 62(2), 59-63.

Townsend E, Wilcock A (2004) Occupational justice. In: CH Christiansen, EA Townsend, eds. Introduction to occupation, the art and science of living. Upper Saddle River, NJ: Prentice Hall, 243-73.

West M, Slater J (1994) Team-working in primary health care: a review of its effectiveness. London: Health Education Authority.

Westhorp P (2003) Exploring balance as a concept in occupational science. Journal of Occupational Science: Australia, 10(2), 99-106.

Whiteford G (2000) Occupational deprivation: global challenge in the new millennium. British Journal of Occupational Therapy, 63(5), 200-204.

Whiteford G (2004) When people cannot participate: occupational deprivation. In: CH Christiansen, EA Townsend, eds. Introduction to occupation, the art and science of living. Upper Saddle River, NJ: Prentice Hall, 221-42.

Wilcock A (2001) Occupational science: the key to broadening horizons. British Journal of Occupational Therapy, 64(8), 412-17.

Wilcock A (2006) An occupational perspective of health. 2nd ed. Thorofare, NJ: Slack.

Wilcock A, Townsend E (2000) Occupational terminology interactive dialogue: occupational justice. Journal of Occupational Science: Australia, 7(2), 84-86.

World Federation of Occupational Therapists (2004) Definition of occupational therapy. Available at: http://www.wfot.org.au/officefiles/ final\%20definitionCM20042.pdf Accessed on 09.05.06.

Yerxa EJ, Clark F, Frank G, Jackson J, Parham D, Pierce D, Stein C, Zemke R (1989) An introduction to occupational science: a foundation for occupational therapy for the 21st century. Occupational Therapy in Health Care, 6(4), 1-17.

\section{Authors}

Anna Pettican, DipHE, BSc(Hons), Senior Occupational Therapist, Placement Assessment and Management Service, South London and Maudsley NHS Foundation Trust, 308-312 Brixton Road, London SW9 6AA. Email: Anna.Pettican@slam.nhs.uk

Wendy Bryant, DipCOT, MSc, PGCertHE, Occupational Therapy Lecturer, School of Health Sciences and Social Care, Mary Seacole Building, Brunel University, Uxbridge, Middlesex UB8 3PH. 